\title{
Entrevista \\ Maria Isabel da Cunha
}

Diálogos sobre a Pesquisa Colaborativa e em Rede:

"o desafio de construir uma caminhada coletiva"

\section{Solange Martins Oliveira Magalhães ${ }^{1}$}

A proposta desta entrevista foi dialogar com a Prof. ${ }^{a}$ Dr. ${ }^{a}$ Maria Isabel da Cunha acerca da Pesquisa Colaborativa e em Rede: ganhos, desafios e perspectivas no campo da pesquisa em educação. A entrevista foi realizada via on-line pela Prof. ${ }^{a}$ Dr. $^{a}$ Solange Martins Oliveira Magalhães, em janeiro de 2021.

\section{Breve currículo da Professora:}

A Professora Maria Isabel da Cunha é graduada em Ciências Sociais (1968) e em Pedagogia (1974) na Universidade Católica de Pelotas. Mestrado em Educação, pela Pontifícia Universidade Católica do Rio Grande do Sul (1979). Doutorado em Educação, pela Universidade Estadual de Campinas (1988). Foi Supervisora Pedagógica na Escola Técnica Federal de Pelotas (1973-1988). Aposentou-se como professora titular da Faculdade de Educação, da Universidade Federal de Pelotas (1975-1999), onde foi coordenadora do PPG Educação (19951997), foi Pró-reitora de Graduação (1989-1992). Fez Estágio de Pósdoutoramento na Universidade Complutense de Madri (1998) e Estágio

1 Doutora em Educação. Professora do curso de Pedagogia e Pós-Graduação em Educação da Faculdade de Educação, Universidade Federal de Goiás (UFG). Goiânia. Goiás, Brasil. Orcid: https://orcid.org/0000-0003-1187-112X. E-mail: solufg@hotmail.com. 
Sênior na Universidade de Sevilha (CNPQ, 2013). Atuou por 17 anos como professora titular do PPG Educação, da Universidade do Vale do Rio dos Sinos (2000-2017). Integra a Rede Sul riograndense de Investigadores da Educação Superior (RIES), com extensa participação em pesquisa e dois Projetos FAPERGS/CNPq/PRONEX. Participou dos Comités de Educação FAPERGS (1989-1992), CAPES (1999-2005) e CNPq (2009-2011) e da Comissão que propôs o SINAES (1992). Atualmente é docente permanente do PPG Educação da Universidade Federal de Pelotas. Tem experiência na área de Educação, com ênfase nos seguintes temas: educação superior, formação de professores, pedagogia universitária e docência universitária. Coordena o Grupo de Pesquisa (CNPq), com vinte anos de atuação e seis livros publicados. Possui Bolsa PQ1 do CNPq.

\section{Para início de Conversa}

[...] um contexto está sempre vinculado à pessoa, ao diálogo infinito em que não há nem a primeira nem a última palavra... (BAKHTIN, 1977, p. 406-7).

A pesquisa colaborativa e em Rede pode ser associada a ideia de cooperação, como imprescindível entre pesquisadores(as) frente ao trabalho coletivo que se propõem na construção de conhecimentos. Nesse sentido, a pesquisa colaborativa tem se mostrado como uma experiência potente no campo da pesquisa em educação, dos quais destacamos alguns aspectos:

- Primeiro, porque investe numa dupla responsabilidade indissociável criar as melhores condições de trabalho e ampliar a capacidade de desenvolver ações para promover aos (às) pesquisadores(as), apoio no desenvolvimento profissional;

- Segundo, sustenta possibilidades de conjunção de pesquisadores(as) e grupos de pesquisadores(as), numa perspectiva multi/inter/transdisciplinar, 
e para sua manutenção exige convivência dialógica, espaço de ação concreta, teórica, reflexiva e interpretativa, na produção do conhecimento;

- Terceiro, amplia o espaço para debate e as possibilidades de aprender e tratar com a diversidade e a complexidade dos fenômenos educativos;

- Quarto, porque um projeto de colaboração é susceptível de motivar os(as) pesquisadores(as) para aprofundamento de estudos, o que ajuda a consolidar um caráter conceitual-metodológico e epistemológico, no âmbito da pesquisa em educação. Motivar também privilegia a socialização, o que envolve agregar postura ética, criatividade, respeito, afetividade, o que, no conjunto, favorece o autoconhecimento, a humanização e a emancipação dos(as) envolvidos(as) em torno da pesquisa;

- Quinto, mas não o último nem o menos importante, pode consolidar um importante formato ao trabalho dos(as) profesores(as)-pesquisadores(as) - coletivo -, sendo aspecto positivo e marcante para o despertar da criatividade, afetividade, trocas, inclusive para fortalecer vínculos na pesquisa, possibilitando aspirações no sentido de práxis.

\section{Para dar sequência a conversa:}

\section{Solange Magalhães:}

Antes de tudo, professora, quero agradecer a sua disposição e disponibilidade em colaborar com o Dossiê Investigação Colaborativa em Rede, da Ensino em Revista/UFU. Destaco sua importância como estudiosa e teórica, quer seja da área de formação de professores(as), como na docência universitária, ou na pedagogia universitária, dentre outros, com uma trajetória inspiradora, digna de respeito e admiração.

Então, para iniciar nosso diálogo, nos fale um pouco sobre a mudança de um formato de pesquisa quase individual para uma pesquisa colaborativa e em rede. Como surgiu e se fortaleceu essa ideia? 


\section{Maria Isabel:}

Já era pesquisadora há muitos anos, inclusive trabalhando coletivamente, mas não havia certeza sobre a intenção da pesquisa colaborativa e em rede. Em 1998, éramos um grupo de professorasinvestigadoras de diferentes Instituições de Ensino Superior do RS, envolvidas com a temática da Educação Superior, que iniciou as discussões e a sistematização de algumas ações, aceitando o desafio de construir uma caminhada coletiva.

Inicialmente nos reuníamos para uma troca de experiências em torno da disciplina de Metodologia do Ensino Superior nas IES gaúchas, mais interessadas em qualificar o ensino do que propor um novo formato de pesquisa em grupo.

As dificuldades enfrentadas na pesquisa, nos remeteu a ideia de solicitar financiamento para a nossa FAPERGS (Fundação de Apoio do Estado) para criarmos um grupo de estudos. A Fundação respondeu que não contemplava esta modalidade, somente apoiava projetos de pesquisa. Então transformamos a proposta inicial do grupo em um Projeto de Pesquisa que se propôs a mapear as iniciativas institucionais envolvidas com a pedagogia universitária nas IES gaúchas.

Conseguimos o apoio da Fundação e esse foi o ponto de partida que originou nossa Rede Sulriograndense de Pesquisadores da Educação Superior - RIES.

\section{Solange Magalhães:}

Quando e como se consolidou a Rede Sulriograndense de Pesquisadores da Educação Superior - RIES?

\section{Maria Isabel:}

No ano de 2000, o grupo se encontrava para estudar temáticas educacionais variadas, mas após o recebimento do fomento, nos deparamos 
com a necessidade de articulação sistemática dos pesquisadores, professores e discentes envolvidos com as pesquisas, o que foi configurando a atual Rede de pesquisa - Sul brasileira de Educação Superior (RIES).

Sua consolidação exigiu uma intencionalidade de construção coletiva que reuniu diferentes IES em trono de um Projeto de Pesquisa abrangente. Nesse percurso buscamos promover: grupos de estudo e debates, wokshops, simpósio de educação, organizados, conjuntamente. Assim, a partir de reuniões que buscavam, inicialmente, inovações da disciplina - Metodologia do Ensino Superior, voltada à docência universitária - ministrada para profissionais de outras áreas que não pedagogia,- encontramos um campo fértil como objeto de estudo da Pedagogia Universitária. E criamos as bases do que hoje compreendemos como sendo a pesquisa colaborativa em rede.

\section{Solange Magalhães:}

Por favor, nos fale um pouco mais da história e do processo de consolidação da RIES:

\section{Maria Isabel:}

Para ter êxito frente às exigências dos Editais, quatro Programa de Pós-Graduação mais consolidados, com pesquisadores mais experientes, formou o "Núcleo Central" da RIES. Na época a PUCRS que capitaneia até hoje a REDE - com a profa. Marilia Morosini, a UFRGS com as professoras Maria Estela Dal Pai Franco e Denise Leite, a UFSM com a profas. Silvia Isaia e Doris Bolzan e eu, Maria Isabel da Cunha, da UNISINOS.

Com o tempo outras pessoas pertencentes aos Programas de outras Instituições foram incorporadas, como também outras Universidades como a Universidade de Passo Fundo, a Federal de Pelotas, a Universidade de Cruz Alta e a Unilassale. Atualmente, desde que me desliguei da UNISINOS, a UFPel compõe o que chamei de núcleo duro da RIES. 
Desde então o Grupo foi se consolidando e enviando projetos às agências de financiamento e, com este apoio, ampliando sua produção e envolvendo um significativo número de estudantes, especialmente mestrandos, doutorandos e pós-doutorandos, contribuindo significativamente para o avanço e difusão do conhecimento no campo da pedagogia universitária.

O grupo ficou fortalecido a partir de várias experiências. A partir de 2001, o Grupo já investia na manutenção do compromisso com "a necessidade de cooperação e compromisso social dos pesquisadores na construção da Educação Superior e da Pedagogia Universitária, como área de conhecimento e de prática profissional" (Informações retiradas do site: https://www.pucrs.br/humanidades/ries/\#historico).

$\mathrm{Na}$ sequência, em 2005, a RIES foi escolhida como Núcleo de Excelência em Ciência, Tecnologia e Inovação do CNPq/FAPERGS, o único Núcleo em educação, composto pelas universidades PUCRS, UFRGS, UFSM e UNISINOS.

A partir deste reconhecimento e apoio, a RIES vem se dedicando à meta análise da área da educação superior, tendo publicado em 2006, pelo INEP/MEC a Enciclopédia de Pedagogia Universitária, v. 2 Glossário.

No contexto de Núcleo de Excelência em Ciência, Tecnologia \& Inovação em Educação, a RIES ainda realizou os seguintes seminários:

1) UFRGS - II Simpósio Nacional de Educação Superior e desenvolvimento profissional - 29 e 30 de junho de 2006. Porto Alegre/RS;

2) PUCRS - IV Seminário Internacional de Educação Superior, Aprendizagem na Educação Superior - Desenvolvimento profissional do docente e o desenvolvimento dos alunos - 9 a 11 de outubro de 2006. Porto Alegre/RS;

3) UNISINOS - V Seminário Nacional de Pedagogia Universitária Educação Superior: desafios e perspectivas dos grupos de pesquisa no contexto acadêmico - de 14 a 16 de maio 2007. São Leopoldo / RS; 
4) UNIFRA/UFSM - IV Simpósio de Educação Superior Desenvolvimento Profissional Docente - I Fórum de pesquisadores em Educação Superior. Santa Maria / RS.

Em 2007, a RIES foi selecionada como Observatório de Educação "Indicadores de Qualidade para a Educação Superior Brasileira" CAPES/INEP. Os objetivos do Projeto eram: configurar e mapear os indicadores de desempenho do sistema de educação superior brasileiro e internacionais relativos à qualidade do ensino superior; selecionar e construir indicadores nas categorias identificadas como denotativas da qualidade da educação superior no país; analisar a qualidade do ensino superior a partir dos indicadores construídos utilizando a base de dados disponibilizada pelo INEP/MEC com possíveis bases complementares; relacionar os indicadores de qualidade do ensino superior construídos pela REDE RIES com o que está posto nas políticas constitutivas da educação superior brasileira.Foi fazendo parcerias internacionais e consolidando a cultura de produção conjunta, e guardando as peculiaridades de cada segmento que compõe a Rede.

Continuamos com Projetos aprovados no contexto do Edital FAPERGS/CNPq/PRONEX que deram um fôlego especial à produção do grupo que a socializa em forma de Seminários abertos, livros e o destaque aos volumes das edições das Enciclopédias da Pedagogia Universitária que está com o novo formato no prelo a ser lançado de imediato.

\section{Solange Magalhães:}

É uma história notável. O que mais a senhora poderia destacar como aspectos positivos na sua experiência da pesquisa colaborativa e em rede?

\section{Maria Isabel:}

Acrescento que a Rede é, em primeiro lugar, um espaço de aprendizagem solidária, muito necessário na academia. Quebra 
competitividades acerbadas e favorece a qualificação das produções pelos múltiplos olhares sobre os objetos do conhecimento.

Favorece a diminuição das hierarquias sem perder a possibilidade do reconhecimento da contribuição de cada participante na medida da sua expertise. Fortalece a compreensão do objeto de estudo de forma mais ampla e na sua maior complexidade, uma vez que conta com energias múltiplas a se debruçar sobre o campo de estudo.

Ensina a partilha e o respeito com a opinião do outro. Exercita a paciência com a diferença e a solidariedade coletiva.

\section{Solange Magalhães:}

Como se dá a produção acadêmica em rede? Poderia nos dizer sobre os processos, avanços, ganhos?

\section{Maria Isabel:}

Creio que não há uma única resposta para essa pergunta. Uma Rede tece uma cultura própria que amalgama experiências anteriores dos participantes e as condições das instituições que albergam a experiência.

Cabe bem as sábias palavras do poeta espanhol Machado...Caminhante não há caminho...o caminho se faz ao caminhar...

É claro que as experiências acumuladas, como já destaquei, pontuando alguns aspectos da história da RIES, podem inspirar aqueles que querem construir Redes de Pesquisa. Mas cada situação vai exigir uma leitura das condições objetivas que envolvem os interesses, os participantes, as possibilidades, as metas, a resiliência. São essas condições que balizam os processos, os avanços, os ganhos.

Mas são elas, também, que ajudam a evitar as dificuldades e minorar o fracasso. 


\section{Solange Magalhães:}

Sobre as relações no trabalho da pesquisa em Rede, como elas se constituem?

\section{Maria Isabel:}

$\mathrm{Na}$ minha opinião, a base de uma Rede é a confiança e a transparência; a partilha nas decisões e o reconhecimento legitimado das lideranças.

\section{Solange Magalhães:}

Poderia nos dizer sobre outras atividades que perpassam o trabalho da pesquisa em rede, como por exemplo, a necessidade dos Grupos de Estudo, debates teóricos, metodológicos?

\section{Maria Isabel:}

Grupos de Estudo podem ser a matriz de um Grupo de Pesquisa; mas não chegam a essa condição; a pesquisa tem características próprias e deve responder à suas configurações. O Grupo de Estudos é mais é mais flexível na sua constituição, considerando a mobilidade de estudantes em um Programa de Pós-Graduação e o próprio interesse dos professores e das Linhas de Pesquisa a que se filiam. O Grupo de Pesquisa se organiza em torno de uma temática que estimula projetos temporalmente definidos, com tarefas e responsabilidades assumidas pelos protagonistas. Exige um compromisso de coesão e responsabilidade partilhada. O Grupo de Pesquisa tem de ter um Projeto comum, ainda que esse possa se desdobrar em subtemas ou subprojetos que estejam sob responsabilidades de subgrupos. Mas é necessário um Projeto unificador.

Uma Rede pode e deve reunir diversos Grupo de Pesquisa - como é o nosso caso na RIES. Os Grupos estão ligados às suas Instituições, aos seus Programas, mas atuam no Projeto da Rede, sem prejuízo de outros Projetos que porventura queiram desenvolver de forma independente ou com outras Redes. 


\section{Solange Magalhães:}

Sobre publicações coletivas, como a rede resolve a questão? Porque há muitos pesquisadores que trabalham efetivamente na pesquisa...

\section{Maria Isabel:}

As publicações coletivas dão corpo e visibilidade à Rede. Elas é que levam ao público o resultado do trabalho produzido de forma articulada e fazem com que a REDE se torne conhecida. Nesse aspecto as próprias agências de fomento exigem e estimulam produções dessa natureza.

As publicações revezam seus autores, aparecendo em vários eventos e outros meios de divulgação. Mas há um compromisso de autoria coletiva distribuída entre os múltiplos produtos que decorrem do grande Projeto da Rede e dos Sub-Projetos dos Grupos que a compõe.

\section{Solange Magalhães:}

Qual o significado deste trabalho para você, seus(suas) orientandos(as) e pares?

\section{Maria Isabel:}

Para mim tem sido de grande aprendizagem participar da construção da RIES e ver essa Rede chegar a um grau de maturidade que nem nós tínhamos previsto no seu nascedouro. Fiz muitas aprendizagens com a equipe da Rede e creio que favoreci ao meu Grupo de Pesquisa - incluindo bolsistas de iniciação científica, mestrandos, doutorandos e pós-doutorandos - a também participar de investigações, eventos e articulações nacionais e internacionais que foram importantes nos seus processos formativos.

Aprendi de tal forma a pesquisar coletivamente que não mais saberia fazer uma investigação solitária. Entendo que a Rede e o Grupo de Pesquisa é um lugar de formação por excelência e que foi uma indução importante do modelo de avaliação da CAPES para a pós-graduação brasileira. 
Mudou muito a cultura da pesquisa nos nossos Programas e nos aproximou entre pares, com as redes públicas de educação e demais Instituições.

Favoreceu que a Universidade se abra mais à comunidade, que envolva parcerias que compreenda que o conhecimento é produzido quando partilhamos ideias, experiências, dúvidas e expectativas.

\section{Solange Magalhães:}

Caminhando para o final dessa entrevista, poderia complementar algo sobre a pesquisa colaborativa e em rede?

\section{Maria Isabel:}

É importante ressaltar que a investigação colaborativa e em rede exige manter um processo formativo, com boa convivência coletiva e colaborativa. Isso consolida um espaço de socialização de dúvidas e experiências, além de influenciar o sentido colaborativo-crítico na realização das investigações com mais segurança e autonomia.

Portanto, com o estabelecimento de um clima de respeito e cuidado, estimula-se o sentimento de pertença ao grupo, o que indica abertura ao outro, conforme preconiza Freire (1998). Sem confiança entre os(as) participantes e sem confiança em si próprios, não haveria trabalho colaborativo em e na Rede.

A investigação colaborativa é enraizada em pressupostos inclusivos e provoca a co-construção e a tomada de consciência dos sujeitos, o que fortalece processos emancipatórios e humanizadores, para além das redes de pesquisa.

Nossa experiência mostra que as redes normalmente se mantêm quando baseadas na ética, mantendo unidas pessoas com diversidade de habilidades e experiência que somam os seus esforços, e, assim, alcançam resultados melhores do que se trabalhasse individualmente. Além disso, as redes de pesquisa são uma das vias mais propícias para o estabelecimento de um espaço multi/inter/transdisciplinar. 


\section{Solange Magalhães:}

Para finalizar, tenho certeza de que essa entrevista vai inspirar outros(as) pesquisadores(as). Sua trajetória deixa marcas de uma vida ética e consolidada teoricamente, mas ela não é maior e nem supera o ser humano e a pessoa inspiradora que a senhora é.

Embora estejamos nos aproximando de uma história que nos reporta a sua vida acadêmica, não há como deixar de dizer do privilégio de dialogar e conviver com a Querida Professora Mabel. Professora de fala mansa, de convivência amorosa, cuidadosa, envolvida com as dificuldades de cada um dos estudantes e pesquisadores.

Sei que se essa entrevista fosse uma carta aberta, na qual outros(as) estudantes, professores(as) e pesquisadores(as) (me incluo aqui) pudessem lhe enviar palavras e carinho, essa entrevista seria uma verdadeira declaração de amor.

Gratidão professora!! 